\title{
Electron Microscopy and Raman Spectroscopy Characterization of Nanoparticle Coated Diatom Biosilica
}

\author{
Timothy Gutu ${ }^{1}$, Debra K. Gale ${ }^{2}$, Wei Wang ${ }^{2}$, Chih-hung Chang ${ }^{2}$, Gregory L. \\ Rorrer $^{2}$, and Jun Jiao ${ }^{1}$ \\ ${ }^{1}$ Department of Physics, Portland State University, OR 97201, USA \\ ${ }^{2}$ Department of Chemical Engineering, Oregon State University, Corvallis, 97331, USA
}

Recently there has been explosive interest in fabricating organic/inorganic hybrid nanostructures with potential novel applications in optoelectronics. Diatoms, singlecelled microalgae, have the unique ability to absorb silicon from its surrounding and convert it into intricate structures that are patterned at both microscale and nanoscale. We utilized a chemical bath deposition technique to coat the highly ornate diatom shells or frustules $\left(\mathrm{SiO}_{2}\right)$ with cadmium sulphide $(\mathrm{Cd})$ to impart novel optoelectronic properties to dielectric material. These hybrid structures have potential applications as optical sensors and photodetectors as well as fabrication of optoelectronic devices. A variety of electron microscopy techniques were used to characterize the morphology and structural properties of the synthesized $\mathrm{CdS} / \mathrm{SiO}_{2}$ composite structures. A Raman microscope was utilized to study the optical vibration modes of the $\mathrm{CdS} /$ diatom composite.

The CdS thin films were deposited on diatom Coscinodiscus wailesii shells at $80{ }^{\circ} \mathrm{C}$ from an aqueous solution of $\mathrm{CdCl}_{2}, \mathrm{NH}_{4} \mathrm{Cl}, \mathrm{CS}\left(\mathrm{NH}_{2}\right)_{2}$, and $\mathrm{NH}_{4} \mathrm{OH}$. The surface morphology of the CdS films was analyzed by SEM at an acceleration voltage of $5 \mathrm{kV}$. An FEI Tecnai F20 TEM was used to study the structural properties. The Raman spectra were measured at room temperature using a Horiba Jobin Yvon Raman microscope. A $532 \mathrm{~nm} \mathrm{Nd}$ :YAG laser was used as the excitation source.

Fig. 1a-c shows a series of FESEM images of diatom Coscinodiscus wailesii biosilica coated with $\mathrm{CdS}$. The images show that the deposited $\mathrm{CdS}$ thin film was nanostructured, adherent, compact and conformal. The 3D shape and pore geometry of the biosilica was preserved. Fig. 1d depicts a low magnification image of a coated diatom frustule. Fig. 1e shows a HRTEM image of the CdS/diatom hybrid structure. The $0.335 \mathrm{~nm}$ lattice fringes correspond to the (002) planes of the CdS hexagonal structure or the (111) planes of the cubic structure. The $0.580 \mathrm{~nm}$ lattice fringes may correspond to the cell lattice parameters of the cubic $\mathrm{CdS}$ or indicate interfacial stress in hexagonal CdS. The SAD micrograph (Fig. 1f) shows that the thin film is polycrystalline. The (hkl) planes obtained from the diffraction pattern were (100), (002) or (111), (101), (102), (110), (103), (112) and (201) which indicated that the CdS was hexagonal. The Raman spectrum of the CdS/diatom composite is illustrated in Fig. 2. The spectrum shows the fundamental characteristic longitudinal optical (LO) phonon peak at about $296 \mathrm{~cm}^{-1}$ (1LO) and its first two overtones at $594 \mathrm{~cm}^{-1}$ (2LO) and $897 \mathrm{~cm}^{-1}$ (3LO). The third harmonic at $897 \mathrm{~cm}^{-1}$ was very weak. The redshift of the phonon peaks is due to the spatial confinement of the phonon modes. In conclusion, novel optical properties were imparted to the unique morphologies of diatom frustules by a simple, inexpensive chemical bath deposition technique and electron microscopy and Raman spectroscopy technique were used to explore the morphology, structural and optical properties of the composites. 

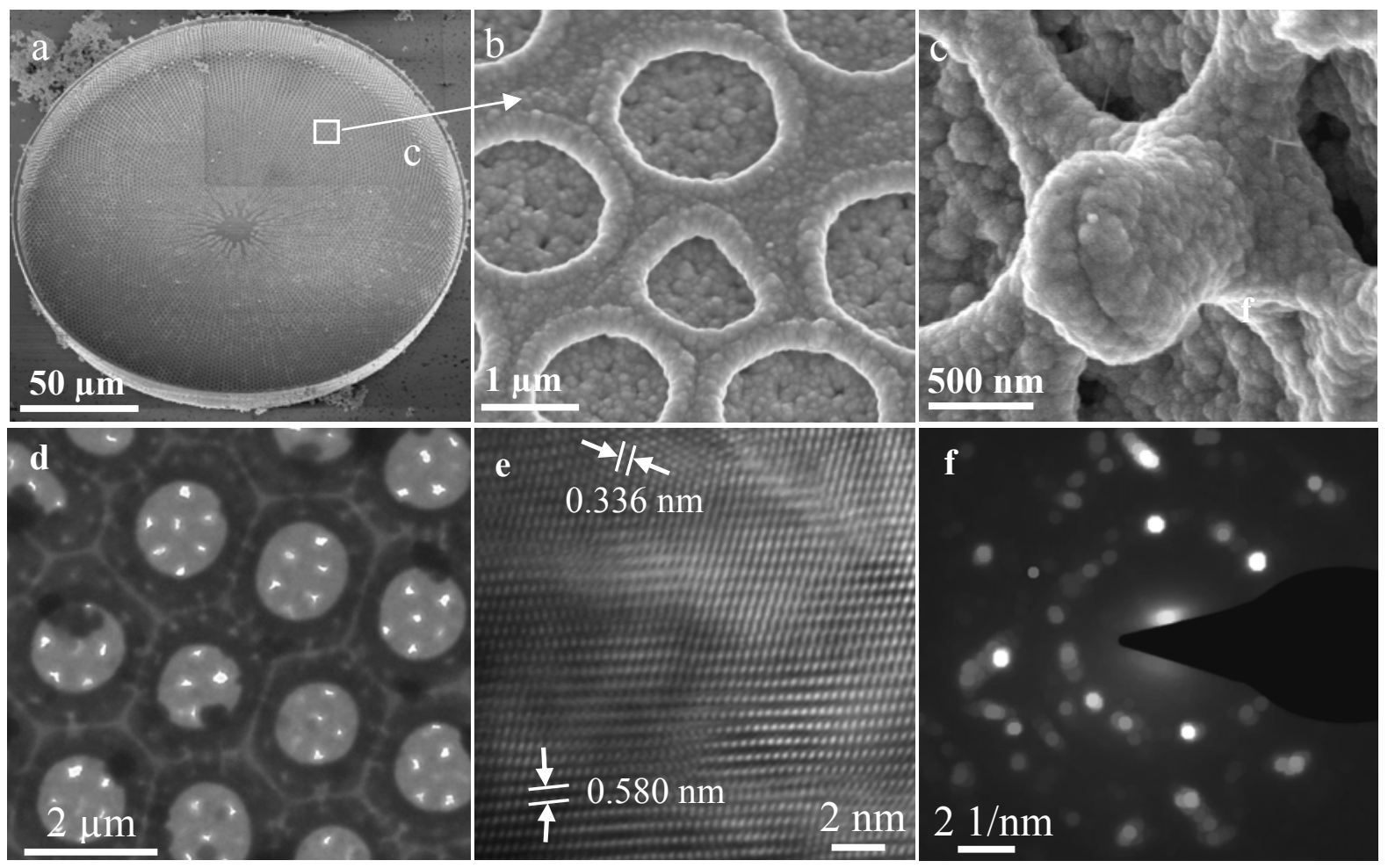

Fig. 1 SEM micrographs of CdS-coated diatom Coscinodiscus wailesii: (a) - (c) The inside view of the valve; (a) Microstructure of full valve, (b) Nanostructured, uniform coating of nanostructures (c) The protuberance was intricately reproduced by a uniform coating (shown by white $\mathbf{c}$ in Fig. 1a). TEM micrographs: (d) A low magnification image of the biosilica with a CdS coating, (e) HRTEM image of the CdS-coated biosilica and (f) Diffraction pattern of (e).

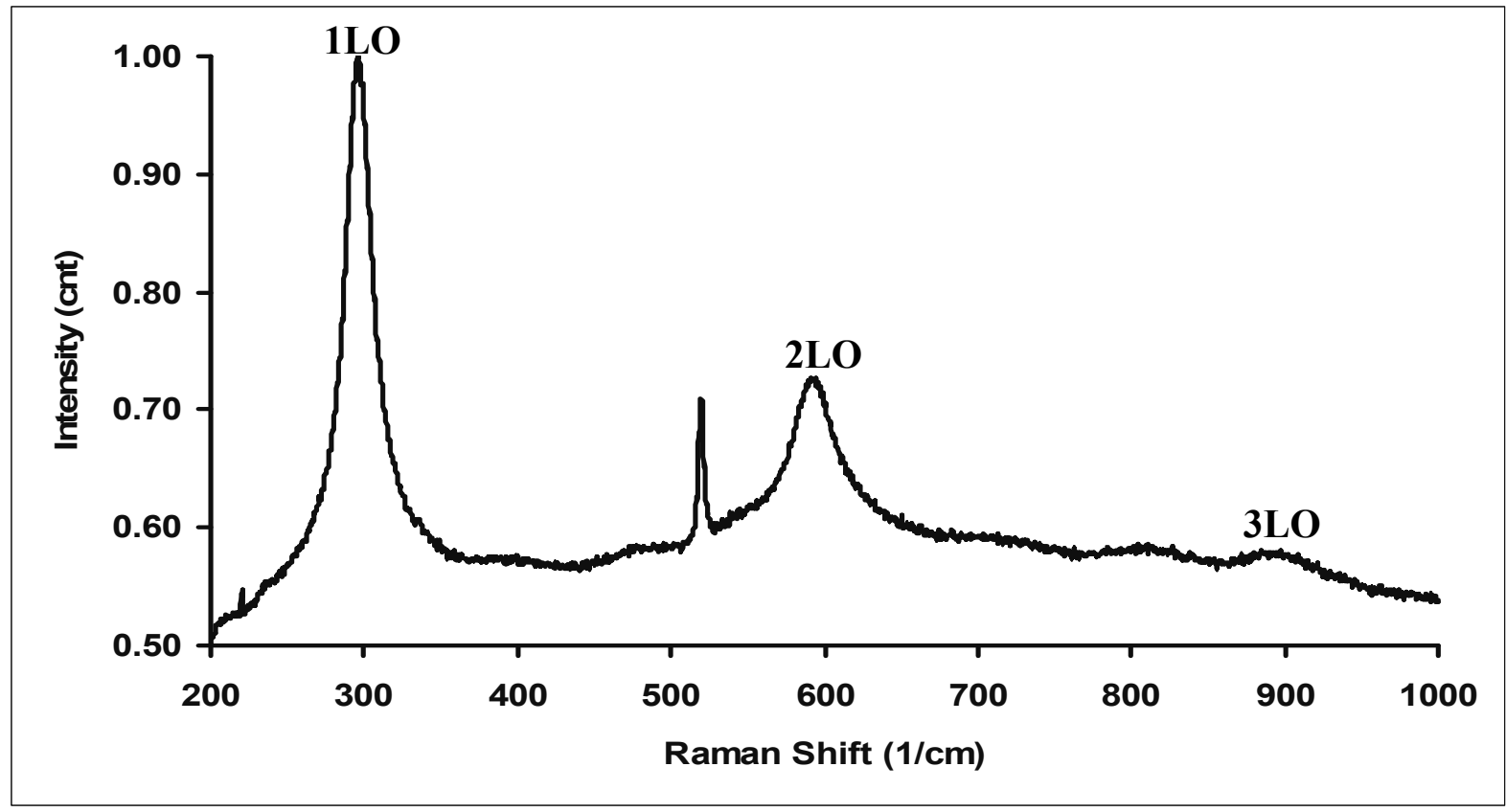

Fig. 2 Raman spectrum of the diatom biosilica with CdS. The peak at $520 \mathrm{~cm}^{-1}$ is an artifact of the glass substrate. 